\title{
A Mediating Model of Emotional Balance and Procrastination on Academic Performance
}

\author{
Pierluigi Diotaiuti ${ }^{\star}$ Giuseppe Valente, Stefania Mancone and Fernando Bellizzi \\ Department of Human Sciences, Society, and Health, University of Cassino and Southern Lazio, Cassino, Italy
}

OPEN ACCESS

Edited by:

Douglas F. Kauffman, Medical University of the Americas -

Nevis, United States

Reviewed by:

Giulia Vettori,

University of Florence, Italy

Lucia Monacis,

University of Foggia, Italy

${ }^{*}$ Correspondence:

Pierluigi Diotaiut

p.diotaiuti@unicas.it

Specialty section:

This article was submitted to Educational Psychology, a section of the journal

Frontiers in Psychology

Received: 19 February 2021

Accepted: 13 September 2021

Published: 13 October 2021

Citation:

Diotaiuti P, Valente G, Mancone $S$ and Bellizzi F (2021) A Mediating Model of Emotional Balance and Procrastination on Academic Performance.

Front. Psychol. 12:665196.

doi: 10.3389/fpsyg.2021.665196
Deficit in the management of time continues to be an important difficulty students are faced with. The present work aimed to test the hypothesis that self-regulation is the major predictor of academic performance and that this effect can be mediated both by the student's emotional regulation and his propensity for procrastination. Participants were 450 university students who were administered MPP and AIP. The procedures involved the administration of instruments and the collection of average exam grades as a measure of academic performance. The effect of a specific component of self-regulation on academic performance, namely action orientation, was significant, while procrastination showed a limiting effect on the performative quality of the student. The model confirmed the mediation role of emotional balance on the effect that action orientation exerts on procrastination, and the mediation of procrastination in the relationship between action orientation and Academic Performance. Results of the study suggest focusing on student support and on prevention of procrastinating behavior through programs that enhance first of all student's proactive attitude, planning skills, self-monitoring and effective/efficient time management, and secondly, emotional awareness and regulation of emotional response in situations of stress and performance anxiety.

Keywords: academic performance, procrastination, self-regulation, emotional balance, mediation model

\section{INTRODUCTION}

Traditionally, procrastination was defined as any behavioral delay in starting or finishing a task (Solomon and Rothblum, 1984; Rothblum et al., 1986; Beck et al., 2000; Meyer, 2000; Ferrari et al., 2005; Klassen et al., 2008). Academic procrastination, according to Steel (2007a) can be defined as the deliberate delay in completing academic assignments even though one is aware of its negative outcomes and consequences (Steel, 2007b). The prevalence of chronic procrastination in students has been reported in numerous studies (Madhan et al., 2012; Day et al., 2014; Kim and Seo, 2015; Visser et al., 2018).

Researchers have consistently identified between $40 \%$ and $60 \%$ of students as involved in procrastination to a moderate or high degree (Onwuegbuzie, 2004). This high prevalence of procrastination appears to be observed similarly across cultures, as reported in the United States (Solomon and Rothblum, 1984; Rothblum et al., 1986; Onwuegbuzie, 2004), Canada and Singapore (Klassen et al., 2009), and Turkey (Özer et al., 2009), Iran (Mohammadi Bytamar 
et al., 2018). Lasane and Jones (2000) examined the relationship between temporal orientation (the predominant tendency to focus attention on a particular region of temporal space) and the frequency of self-reported academic procrastination. They hypothesized that students classified as either high in present time orientation or high in future time orientation would differ in their likelihood of experiencing socially induced temporal myopia, namely the degree to which short-term social events would interfere with academic goal-setting. High in present time oriented students resulted to procrastinate more and had worse performance. Often the student finds himself to starts working shortly before the deadline, procrastinating until the last possible moment to start an activity; when they have to prepare for an exam, they think they are taking less time than they have available, they concentrate their efforts towards the end of the estimated time and are often reduced to working in a hurry to make a last-minute submission (Patrzek et al., 2012).

Procrastination could even be considered a tactic to protect the subject's vulnerable self-esteem. Various studies have shown a significant association between procrastination, low confidence and self-esteem, high levels of anxiety, depression, neurosis, forgetfulness, disorganization and lack of energy (Effert and Ferrari, 1989; Stöber and Joormann, 2001). Procrastinators are apparently more inclined to self-handicapping behavior; they use techniques that manipulate the impression they make on others and avoid any information that will lead to a realistic diagnosis of themselves (Ferrari, 1991).

Some researchers state that procrastination is highly correlated with the failure of self-regulation (Baumeister et al., 2007; Howell and Watson, 2007; Steel, 2007a; Pychyl and Flett, 2012; de Palo et al., 2017; Ziegler and Opdenakker, 2018). Baumeister and Heatherton (1996) have defined the failure of self-regulation as a wrong action committed by a person (sub-regulation) or an individual taking ineffective action (wrong self-regulation) in an attempt to initiate, alter or inhibit behavior. Some researchers approach procrastination as a form of sub-regulation: procrastinators fail to set standards, monitor performance and maintain motivation (Ferrari, 2001; Rabin et al., 2010). In the study by Garzón-Umerenkova et al. (2018) there is a description of the current models of the relationship between the variable SR (Self-Regulation) and procrastination (dysregulation). An interesting, recent general model that emphasizes the importance of the cyclical aspect of individual self-regulation (SR) and the external regulation derived from the context (ER), intended as different and complementary variables both in combination and interaction, is proposed by de la Fuente-Arias (2017) as Theory of Self- vs. Externally-Regulated Learning. As suggested by de la Fuente et al. (2020), Self-Regulation (SR) should be considered a personalistic variable or meta-ability and a behavioral materialization of personality factors. The study by de la Fuente et al. (2015) is significant with regard to the relationships between SR (considered a metabehavioral variable) and other meta cognitive and meta emotional variables. Other researchers believe that procrastinators engage in misregulation and procrastination actions as an emotional regulation strategy to repair bad moods caused by the task at hand (Tice et al., 2001; Sirois and Pychyl, 2013). Emotion regulation plays a critical role in understanding the self-regulatory failure of procrastination. Individuals postpone or avoid aversive tasks in order to gain short-term positive affect at the cost of longterm goals (Tice and Bratslavsky, 2000). With regard to the details of this process, Sirois and Pychyl (2013) have suggested considering counterfactual thinking as an explanation of emotional misregulation that may promote procrastination. As aversive affective states have been shown to cue procrastination by misregulation, it was hypothesized that the ability to adaptively cope with aversive affective states reduces the risk of procrastination (e.g., Blunt and Pychyl, 1998). Eckert et al. (2016) aimed to clarify the role of emotion regulation skills in order to reduce the tendency of procrastination.

Regarding the field of academic procrastination, GarzónUmerenkova et al. (2018) indicate in their structural relationship model that self-regulation predicts procrastination in students directly and their level of academic performance indirectly. The study also reports that compared to the gender variable, women tend to procrastinate less and show a greater involvement (flourishing) in academic performance. A specific in-depth study in the literature (also quoted in the same article) on the differences between men and women regarding the intensity and type of procrastination is reported in Özer et al. (2009). A further recent contribution showed that both different personality traits and gender play a significant role in behaviour (Zhou, 2020). Duckworth et al. (2019) have also shown that low self-control causes procrastination. Students with high selfcontrol are aware of their learning process and are more successful in balancing and speeding up their tasks. Currently, there are also several lines of research that analyse individual non-cognitive factors that increase the prediction of academic performance. Greater emotional regulation and a better process of adaptability are useful to cope with academic stress and achieve academic success (Saklofske et al., 2012). With regard to the (moderate) association between socio-emotional intelligence and academic performance see the recent metaanalytic study by Sánchez-Álvarez et al. (2020). As regards the relationship between procrastination and emotional regulation the results of the study by Mohammadi Bytamar et al. (2020) are also significant, as they show that procrastination is positively associated with problems in emotional regulation. This finding is in line with models that consider emotion regulation as self-regulation failure in procrastination (Pychyl and Sirois, 2016).

Literature models on the one hand therefore converge in stating that procrastination is essentially determined by a failure of self-regulation (Baumeister et al., 2007; Howell and Watson, 2007; Steel, 2007a; Pychyl and Flett, 2012; Ziegler and Opdenakker, 2018), on the other hand, there is simultaneously a line of studies that considers the role of emotion regulation on procrastination behaviour to be decisive (Ferrari, 2001; Tice et al., 2001; Pychyl and Sirois, 2016; Mohammadi Bytamar et al., 2020). Starting from this theoretical framework, in this study we firstly hypothesized that the student's emotional balance could have a mediating function on the relationship between self-regulatory competence and procrastination behaviour; secondly, considering also the measure of academic performance (the grades of the exams taken), we hypothesized a serial 
mediation model where, the main relationship between selfregulation and academic performance were mediated by the student's emotional balance (first mediator) and procrastination tendency (second mediator).

\section{MATERIALS AND METHODS}

\section{Participants}

450 Italian university students were involved in the study: 237 (52.7\%) males and 213 (47.3\%) females, $\mathrm{M}$ age 22.25, SD age 2.87. Students voluntarily agreed to participate in the study after being informed of its objectives and they all supplied an adequate compilation of the instrument. Participants covered a substantially equal number of students attending science (56\%) and humanities courses (44\%). As a criterion for inclusion, enrolment in the third year of the course was considered, in order to include participants who were not beginners but who already have a well-structured approach and attitude towards university study and were not conditioned by the transition from high school to university. The administration of the instruments was done through an on-site group procedure.

\section{Tools}

\section{Two tools were Administered:}

1. Multidimensional personality profile (MPP; Caprara et al., 2006), developed from the two dominant models in the psychology of personality: the social-cognitive theory and the theory of traits. The test measures five fundamental areas of personality: Agentivity, Social-Emotional Intelligence, Self-regulation, Ability to Cope (with critical situations), Innovation. Each of these areas is divided into sub-dimensions that analyze its content by anchoring it directly to behaviors, subjective states and significant external criteria. The test consists of 152 statements with which it is necessary to express one's degree of agreement on a five-level scale. For the purposes of this work, the Socio-emotional intelligence (Empathy, Prosociality, Sociability, Interpersonal Confidence), Self-regulation (Action Orientation, Tenacity, Reliability, Accuracy) and Ability to Cope (Emotional Balance, Stress Management, Negative Emotion Management, Resilience) scales were administered. Reliability measures through McDonald's omega and Cronbach's alpha were both 0.84 , $0.82,0.76$, respectively. Considering the theoretical models of reference of the study and the mediation relations hypothesised, the choice of this instrument, compared to other personality tests validated in Italian, was motivated by the possibility of measuring in the student both selfregulation with its components (Action Orientation, Tenacity, Reliability, Accuracy), and the various aspects linked to the ability to cope and manage emotions.

2. Adult inventory for procrastination (AIP, McCown and Johnson, 1989; It.valid. Mariani and Ferrari, 2012); the AIP scale measures the chronic tendency to postpone tasks in various situations. It examines procrastination motivated by fears (e.g., success or failure), the avoidance of disclosure of skill inabilities, and performance insecurity. The tool assesses avoidance procrastination; that is, putting off tasks to protect one's self-esteem from possible failure. The AIP is composed of 15 Likert-scale items such that respondents express an opinion on a 5 -point scale $(1=$ strongly disagree; $5=$ strongly agree) to statements such as "I am not very good at meeting deadlines" and "I do not get things done on time." Both reliability measures for McDonald's omega and Cronbach's alpha were 0.80 .

3. In addition to the administration of the psychometric tools, participants were asked to report their own academic performance, which corresponds to the average of the grades obtained in the examinations. University exam grades in Italy range from a minimum of $18 / 30$ to a maximum grade of $30 / 30$. In order to avoid being inaccurate in remembering their grade point average, students were asked to consult their digital profile on the university portal, where this data is available.

\section{Procedures}

Students voluntarily agreed to participate in the study after being informed of its objectives and they all supplied an adequate compilation of the instrument. They were also informed of the anonymity of the test and the fact that it was designed for research purposes only. The protocol was approved by the Institutional Review Board of the local university. Tools administration took place upon the release and signing of the form for an informed consent of participation.

\section{STATISTICAL ANALYSIS}

Descriptive statistics were performed to illustrate socio-demographic information (gender, age, study area); Pearson and Spearman bivariate correlations, significant at $p<0.005$ and at $p<0.0012$-tailed, were used to measure the association between the main variables (Socio-Emotional Intelligence, Self-Regulation, Ability to Cope, Procrastination); Cronbach's alpha and McDonald's omega were considered as scale reliability coefficients; $T$-test was used to explore significance in procrastination behaviors relating to gender; ANOVA univariate test with Post-hoc Tukey HSD and $p<0.05$ to explore associations between Procrastination, Emotional Balance and SelfRegulation; a hierarchical regression was performed to identify the predictors of procrastination and academic performance; a simple mediation analysis was run to test the function of Emotional Balance on the effects of Procrastination on Academic Performance; a serial mediation analysis was run to test the effects of Emotional Balance and Procrastination in the relationship between ActionOrientation and Academic Performance. Association and prediction analyses were performed using the packages SPSS v. 22, while mediation analyses were performed through the PROCESS macro version $2.3^{1}$ (Hayes, 2017). As the Process macro procedure shows the unstandardized beta values, all varibles were standardized before to run mediational analyses.

${ }^{1}$ www.processmacro.org 


\section{RESULTS}

\section{Relations of Association}

The Table 1 shows the bivariate correlations between the main variables of the study.

Taking into consideration performance in the studies, that is, the average grades of successful exams (whereas in Italy the academic grades range from a minimum of 18 to a maximum of 30), significant association resulted with the level of procrastination. A greater level of Procrastination was significantly associated with a lower Academic Performance: $F(1,449)=3.981 p=0.04 ; \eta^{2}=0.03$.

Considering the level of procrastination within the sample as a function of gender, a significant result emerged upon examination of the $t$-student test: $\mathrm{t}(448)=2.457 p=0.02 ; d=0.40$. Male procrastination was significantly higher $\left(M_{\mathrm{m}}=2.66 ; \mathrm{SD}=0.61\right)$ than the female one $\left(M_{\mathrm{f}}=2.39 ; \mathrm{SD}=0.74\right)$. It was then investigated whether the trait components helped to explain the overall procrastination orientation, also according to the gender of the participants. Among the MPP measures considered, significance was found in association with Emotional Balance and Self-Regulation. A greater level of Emotional Balance was significantly associated with a lower propensity for Procrastination: $F(1,449)=37.937$ $p=0.000, \eta^{2}=0.20 ; \mathrm{OP}=0.99$. At the same time, a greater level of Self-Regulation was significantly associated with a lower propensity for Procrastination: $\mathrm{F}(1,449)=21.020 p=0.000, \eta^{2}=0.12$; OP $=0.99$. The interaction between the two variables (Emotional Balance ${ }^{\star}$ SelfRegulation) was also significant: $F(3,449)=8.948 p=0.003, \eta^{2}=0.06$; $\mathrm{OP}=0.84$. Corrected model: $F(3,449)=20.645 p=0.000, \eta^{2}=0.30$; $\mathrm{OP}=0.99$.

Taking into account the males alone, among the MPP measures significance was found in association with Emotional Balance. A greater level of Emotional Balance was significantly associated with a lower propensity for Procrastination: $F(1,236)=21.109$ $p=0.000 ; \eta^{2}=0.21 \mathrm{OP}=0.99$. Whereas for the females, significance resulted between Procrastination and Self-Regulation. A lower level of Self-Regulation corresponded to a greater propensity for procrastination: $F(1,212)=15.601 p=0.000 ; \eta^{2}=0.18 \mathrm{OP}=0.97$.

\section{Predictors and Mediators of Procrastination \\ Relations of Prediction}

Subsequently, in order to identify the predictors of Procrastination, a hierarchical regression was carried out by inserting as potential predictors the variables that had shown significance in the analysis of previous variance. The assumptions of multivariate normality were first verified: standardized mean residuals $=0.000 ;$ Durbin -Watson $=2.169 ;$ VIF $<1.2$; Tolerance $>0.84 . \quad F(1,449)=22.192 ; \quad p=0.000 ; \quad R^{2}=0.331$. Significant predictors of Procrastination were a lower level of Self-Regulation $\left(\Delta \mathrm{R}^{2}=0.21 ; \beta=-0.328\right)$, lower Emotional Balance $\left(\Delta \mathrm{R}^{2}=0.06\right.$; $\beta=-0.303)$, and Gender $\left(\Delta \mathrm{R}^{2}=0.05 ; \beta=-0.217\right)$.

\section{Mediation Relations}

Considering the first hypothesis of the study, in order to assess the estimates of the relationship between predictors, a mediation analysis was carried out to test if emotional balance plays a mediating role in the relationship between self-regulation and student procrastination.

Results from a simple mediation analysis indicated that Self-Regulation is indirectly related to Procrastination through its relationship with Emotional Balance. First, as can be seen in Figure 1, self-regulation has a positive estimate on the emotional balance $(a=0.378, p=0.000)$, and a higher reported emotional balance was subsequently related to less procrastination ( $b=-0.266, p=0.000)$. A 95\% bias-corrected confidence interval based on 10,000 bootstrap samples indicated that the indirect effect $(a b=-0.100)$ was entirely below zero $(-0.172$ to -0.037$)$. Moreover, higher levels of self-regulation corresponded to lower procrastination even after taking into account SR's indirect effect through Emotional Balance $\left(C^{\prime}=-0.513, p=0.000\right)$.

This result therefore confirmed the first hypothesis of the study.

\section{Predictors and Mediators of Academic Performance Relations of Prediction}

In order to identify the predictors of Academic Performance, a hierarchical regression was carried out by inserting as potential predictors the variables that had shown significance in the analysis of previous variance. Significant predictors of Academic Performance were a higher level of Action-Orientation $\left(\Delta \mathrm{R}^{2}=0.028 ; \beta=0.174\right)$, lower Procrastination $\left(\Delta \mathrm{R}^{2}=0.053 ; \beta=-0.179\right)$.

\section{Mediation Relations}

Considering the second hypothesis of the study, a general explanatory model was tested through a serial mediation analysis of the effect of Action Orientation on Academic Performance. The results, as shown in Figure 2, indicated that ActionOrientation was indirectly related to Academic Performance

TABLE 1 | Variables means and bivariate correlations.

\begin{tabular}{|c|c|c|c|c|c|c|c|c|}
\hline & Mean & SD & Sk & Ku & PR & SR & EB & AP \\
\hline Procrastination & 2.53 & 0.69 & -0.24 & -0.38 & 1 & & & \\
\hline Self-Regulation & 3.38 & 0.48 & 0.40 & -0.19 & $-0.455^{* *}$ & 1 & & \\
\hline Emotional Balance & 3.18 & 0.73 & 0.26 & -0.18 & $-0.400^{* *}$ & $0.378^{* *}$ & 1 & \\
\hline Academic Performance & 24.81 & 2.31 & 0.21 & -0.39 & $-0.287^{* *}$ & $0.222^{*}$ & $0.191^{*}$ & 1 \\
\hline Socio-Emotional Intelligence & 3.25 & 0.37 & 0.14 & -0.11 & -0.125 & $0.255^{* *}$ & $0.286^{* *}$ & $-0.253^{* *}$ \\
\hline
\end{tabular}

SD, standard deviation; Sk, skewness; Ku, kurtosis. ${ }^{* *}$ Correlation is significant at the 0.01 level (2-tailed). " Correlation is significant at the 0.05 level (2-tailed). For AP Spearman's correlation has been used. PR, Procrastination; SR, Self-Regulation; EB, Emotional Balance; AP, Academic Performance; El, Socio-Emotional Intelligence. N=450. 


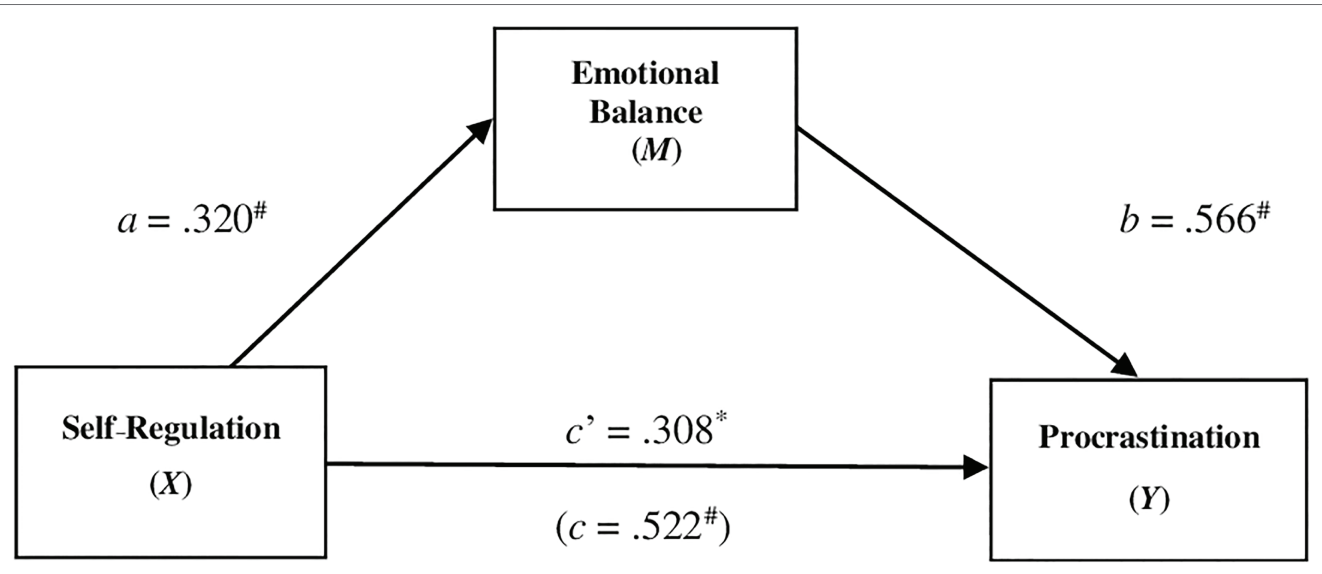

FIGURE 1 | The mediating effect of emotional balance in the relationship between Self-Regulation and procrastination. ${ }^{*} p<0.001$, ${ }^{p} p<0.05$; all presented effects are unstandardized; $a$ is effect of Self-Regulation on Emotional Balance; $b$ is effect of Emotional Balance on Procrastination; $C$ ' is direct effect of Self-Regulation on Procrastination. $C$ is total effect of Self-Regulation on Procrastination.

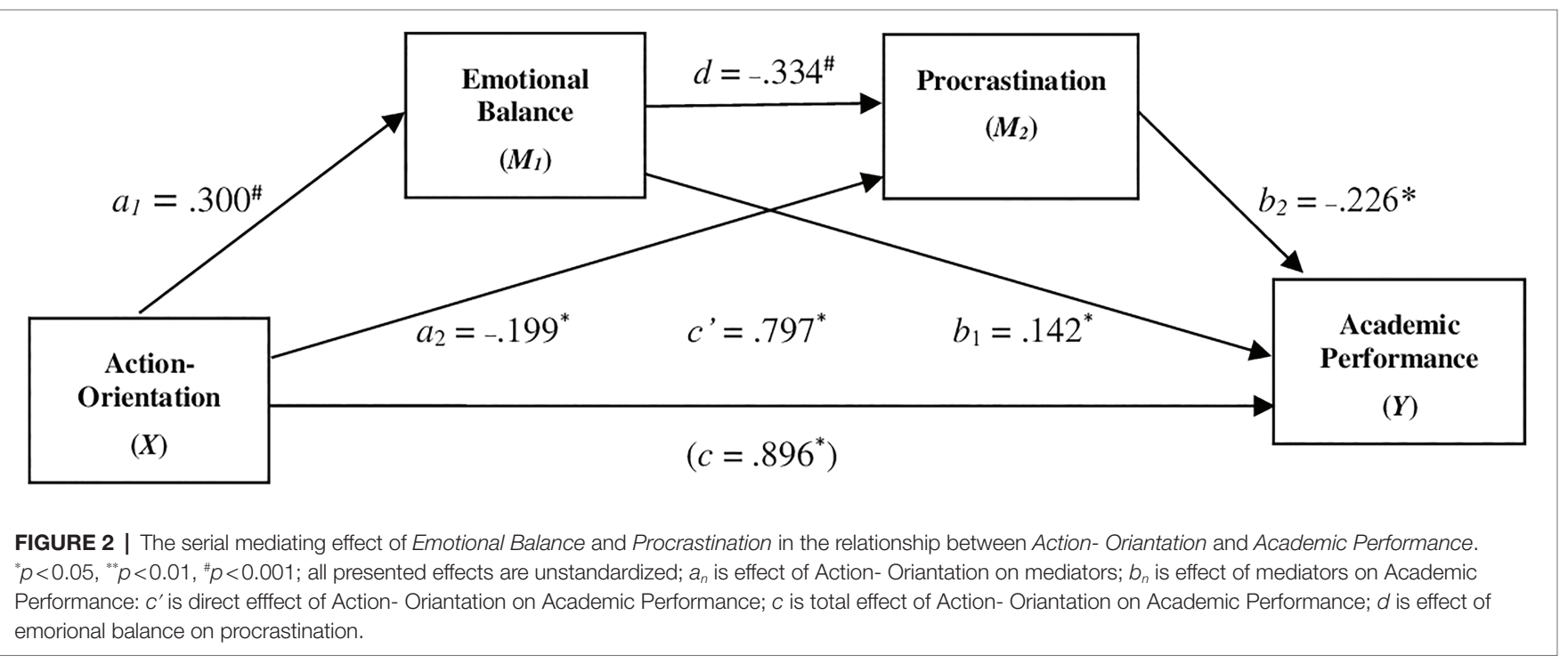

through its relationship with Emotional Balance and Procrastination. First, as can be seen in Figure 2, ActionOrientation had a positive estimate on Emotional Balance $\left(a_{1}=0.300, p=0.000\right)$, and a higher reported Emotional Balance was subsequently related to more Academic Performance $\left(b_{1}=0.142, p=0.048\right)$. A 95\% bias-corrected confidence interval based on 10,000 bootstrap samples indicated that the indirect effect through Emotional Balance $\left(a_{1} b_{1}=0.043\right)$, keeping the other mediator constant, was entirely above zero ( 0.024 to 0.119). Second, Action-Orientation had a negative effect on Procrastination $\left(a_{2}=-0.199, p=0.018\right)$, and a higher reported Procrastination was subsequently related to less Academic Performance $\left(b_{2}=-0.226, p=0.016\right)$. A $95 \%$ bias-corrected confidence interval based on 10,000 bootstrap samples indicated that the indirect effect through Procrastination $\left(a_{2} b_{2}=0.045\right)$, keeping the other mediator constant, was entirely below zero (0.003 to 0.103). Third, Emotional Balance (first mediator) had a negative effect on Procrastination (second mediator; $d=-0.334, p=0.000)$, and the indirect effect through both mediators $\left(\mathrm{a}_{1} \mathrm{db}_{2}=0.023\right)$ was entirely below zero (0.002 to 0.057). Furthermore, higher levels of Action-Orientation corresponded to higher Academic Performance even after taking into account Action-Orientation's indirect effect through Emotional Balance and Procrastination $\left(C^{\prime}=0.797, p=0.025\right)$.

This result therefore also confirmed the second hypothesis of the study.

\section{DISCUSSION}

The results of the study firstly confirmed the evidence in literature of the prevalence of procrastination behaviour in male students (Steel, 2007a; Özer et al., 2009; Steel and Ferrari, 2013; Mandap, 2016; Balkis and Duru, 2017; Limone et al., 2020). It was also found that in male procrastination there were reasons mainly related to emotional regulation, whereas 
in female procrastination there were significant self-regulatory aspects, such as those related to planning and time management, namely the action orientation. Probably in males it would affect a lower ability to use strategies to control states of anxiety and stress, sense of loneliness and frustration, depressive states and negative mood that often involve students in the college path. Goubet and Chrysikou's (2019) recent study generally highlights a smaller repertoire of emotional regulation strategies and significantly less flexibility of implementation in males compared to females. Failing to fully accept and cope with their negative states, male students are likely to defend themselves through systematic avoidance, impulsively channeling their energies into social, sporting, playful, virtual, video games, and gambling activities, thereby distancing themselves from the academic task (Zhong, 2013; Petruccelli et al., 2014; Nordby et al., 2019; Shi et al., 2021). This impulsive tendency towards self-distraction and defocusing progressively lowers the level of engagement and motivation to study (Wypych et al., 2018; Svartdal et al., 2020). Instead, the results regarding the variables associated with female procrastination emphasize a limitation in the ability of self-management and pragmatic orientation towards the goals to be achieved. According to several studies, fear of failure and lack of self-regulated learning strategies would be the factors significantly attributable to female procrastination in university contexts (Özer et al., 2009; Abdi Zarrin et al., 2020; Limone et al., 2020). The tendency to perfectionism with its maladaptive aspects (see Ghosh and Roy, 2017; Newman et al., 2019), could also negatively affect a balanced and pragmatic assessment of the most effective actions to take towards the main goal. Action orientation is actually defined as the ability to plan and monitor a course of action in order to achieve a specific objective. Depending on the task and context in which it is found, the student will have to make an estimate of the time and effort required to carry out the assignment (see Sharaf et al., 2016; Alsalem et al., 2017). Nevertheless, deficit in time management continues to be an important difficulty that students have to face. Students with low results can make mistakes in evaluating how much study time is needed to assimilate the more difficult subjects (Broadbent, 2017; He and Zhang, 2019). Sometimes this is linked to the fact that students establish unrealistic objectives and are not in a condition to be able to evaluate the actual time needed for acquiring the skills and knowledge (Morgan, 1985; Gustavson and Miyake, 2017; Jalagat, 2017).

Results of the study showed also the significance of an initial model of mediation in which the student's emotional balance played a role in mediating the effect of self-regulation on procrastination. Emotional balance represents the ability to control the influence of one's mood and emotions on one's behavior. This highlights that both the cognitive regulation component (SR) and the emotional regulation component are elements that could condition the procrastination behaviour, but above all that the student's emotional balance can increase the effect of the control of organizing and planning the work that must be done to pass the exams.

Various studies have shown a significant association between procrastination, low confidence and self-esteem, high levels of anxiety, depression, neurosis, forgetfulness, disorganization and lack of energy (Effert and Ferrari, 1989; Garzón-Umerenkova et al., 2020). Procrastinators are apparently more inclined to self-handcapping behaviours; they use techniques that manipulate the impression they make on others and avoid any information that will lead to a realistic diagnosis of themselves (Ferrari, 1991; Ferrari and Tice, 2000). In addition, the relationship established with self-handicap behaviors, seems to provide evidence regarding the consideration of procrastination and self-handicap as a dysregulatory behavior, considered by the recent SRL vs. ERL Theory (de la Fuente-Arias, 2017).

The results of our study showed that emotional balance is a key competence for the student. They agree with Pychyl and Sirois (2016)and Wypych et al. (2018), who emphasize the role of emotion regulation and stress coping in procrastination. Procrastination was postulated to result from negative emotions, such as fear of failure (Schouwenburg, 1992) or discomfort intolerance (Harrington, 2005). Accordingly, highly procrastinating students were found to be much more sensitive to punishment than their non-procrastinating colleagues (Michałowski et al., 2017). Additionally, various negative emotions related to tasks were shown to lead to the avoidance of those tasks (Blunt and Pychyl, 2000).

The second model in our study included a performance measure relating to the average marks that students received at the examinations. As can be seen in Figure 2, with regard to the performance variable the estimate of a specific component of self-regulation, namely action orientation, was significant, while procrastination reported a negative association with the performative quality of the student. This result is consistent with other recent studies (Hen and Goroshit, 2014; Kyung and Eun, 2015; Yilmaz, 2017; Asadzadeh, 2018; Goroshit, 2018; Bashir and Gupta, 2019). The model reported a mediation role of emotional balance on the estimated effect of action orientation on procrastination; at the same time, a negative and significant relationship between emotional balance and academic performance. This suggests that a low regulation capacity of the emotional sphere would indirectly have (via procrastination) consequences of limiting the quality of academic performance. These relationships would distinguish this study from those which have instead only hypothesized a direct relationship between emotional dysregulation and academic performance (see Crego et al., 2016; Frazier et al., 2018; Vizoso Gómez et al., 2018; Morales-Rodríguez and Pérez-Mármol, 2019).

As already pointed out by Dresel et al. (2015), resources management strategies, i.e., the ability to manage external resources, are just as important as internal emotional control., as in seeking for help, or organizing one's workplace, as well as to managing and regulating internal resources, such as effort regulation, time management, attentional regulation, and motivation. In the university context of the last two years, the transition from face-to-face to remote teaching, as a result of the limitations of the covid-19 pandemic, has strongly emphasized the need for students to possess pronounced selfmanagement skills in their learning processes in order not to fall behind on scheduled paths and deadlines and also to maintain a good level of perceived psychological well-being 
(Pelikan et al., 2021; Diotaiuti et al., 2021a). It has been observed in several studies how distractions at home and reduced social interaction with other students and faculty can negatively affect study time management and adaptation to the new emergency condition that requires students to have a higher level of autonomy and metacognitive control (Rasheed et al., 2020; Tezer, 2020; Alyami et al., 2021; Biwer et al., 2021; Diotaiuti et al., 2021b).

\section{IMPLICATIONS OF THE STUDY}

The results of this study suggest that student support and procrastination behavior prevention interventions should focus on programs that enhance first of all the student's proactive attitude, planning skills, self-monitoring and effective/efficient time management, and secondly, emotional awareness and regulation of emotional response in situations of stress and performance anxiety.

In the literature, as reported by Goroshit (2018), few programs have focused on limiting student procrastination (Bui, 2007; Rakes and Dunn, 2010; Grunschel et al., 2016; Stewart et al., 2016; Deleval et al., 2017); but emotion regulation training has been shown to reduce procrastination (see Eckert et al., 2016; Van Eerde and Klingsieck, 2018). Awareness of the problem should therefore be accompanied by a willingness to build and validate effective programs in the field. The literature has indicated that it is also necessary to consider potentially influential situational variables, such as the degree of satisfaction associated with the learning context, living (or not) in a university residence, a distance learning environment, the specific needs of the person, individual beliefs and expectations (Rustemeyer and Rausch, 2007; Medrano et al., 2016; Yilmaz, 2017; Goroshit, 2018). An innovative and effective intervention program should therefore include the control and manipulation of these aspects.

Students should be guided by experienced counsellors to increase their effort and persistence, and optimize self-control together with emotional balance. In this regard, it is important to use a communicative style adapted to the current needs of students and able to functionally affect their attitudes towards study and their life project (Daulay et al., 2018; Maddineshat et al., 2019; Diotaiuti et al., 2020). Such target programs could improve not only students' academic life, but also their general well-being. The work on students' self-regulation concerns the enhancement of the individual's capacity for planning and persistence in achieving a goal, self-discipline, understood both as a self-reflective ability to organize and as tenacity for success, a love of order and precision which is distinguished by the desire to do things well (Colthorpe et al., 2017; Broadbent and Fuller-Tyszkiewicz, 2018; Bernardo et al., 2019).

Future studies could also try to understand if and how students' temporal perspectives or temporal foci may also play a role among the predictors of university procrastination (Baguri et al., 2020; Levasseur et al., 2020; Diotaiuti et al., 2021c). In this case, a university couselling programme should also include an in-depth examination of the value of the person's temporal perspective and the importance of the focus of attention that the student mainly devotes to the declinations of his/her own time (past, present and future).

\section{LIMITATIONS OF THE STUDY}

Although this study yielded significant findings, some limitations should be considered. First, the use of self-report measures, exposed to the risk of underestimation of the reported procrastination reported by the students. Moreover, this was a cross-sectional research study in which the data were collected in a specific time period. Therefore, it is suggested that further research be carried out longitudinally to determine the level of procrastination behaviors among students, by also expanding the sample to students from other universities and geographical areas. Given the cross-sectional design, the research dealt with the associations between self-regulation, emotional balance, academic procrastination, and academic performance, and not with causes and effects. Nevertheless, given that the crosssectional design does not inform on causation, the obtained mediations are an estimate that does not contradict the mediations relationships, although they do not prove them (Maxwell and Cole, 2011). Results should therefore be interpreted considering that the effects are compatible with the hypothesized theoretical models, while the direction remains open and this must be possibly demonstrated both theoretically and with more suitable research designs. Future investigations should carry out experimental designs to examine more specifically effect directions.

Finally, a further limitation is that this research is located at a molecular level and therefore does not allow the integration of real contextual variables of the teaching process, which are very important in the psycho-educational analysis of selfregulation and procrastination. Consequently, a further level of analysis is needed in order to offer a contextualized, interactive view of the object of study.

\section{DATA AVAILABILITY STATEMENT}

The raw data supporting the conclusions of this article will be made available by the authors, without undue reservation.

\section{ETHICS STATEMENT}

The studies involving human participants were reviewed and approved by Institutional Rewiew Board of the University of Cassino and Southern Lazio. The patients/participants provided their written informed consent to participate in this study.

\section{AUTHOR CONTRIBUTIONS}

PD, GV, and SM designed the study. PD, GV, and SM analyzed the data and discussed the results. PD, GV, and 
FB drafted the manuscript. SM, FB, and GV revised the manuscript. Finally, the authors have agreed to be accountable for all aspects of the manuscript in ensuring that questions

\section{REFERENCES}

Abdi Zarrin, S., Gracia, E., and Paixão, M. P. (2020). Prediction of academic procrastination by fear of failure and self-regulation. Educ. Sci. Theory Pract. 20, 34-43. doi: 10.12738/jestp.2020.3.003

Alsalem, W., Alamodi, L., and Hazazi, A. (2017). The effect of time management on academic performance among students of Jazan University. Egyptian J. Hospital Med. 69, 3042-3049. doi: 10.12816/0042853

Alyami, A., Abdulwahed, A., Azhar, A., Binsaddik, A., and Bafaraj, S. (2021). Impact of time-management on the Student's academic performance: A cross-sectional study. Creative Edu. 12, 471-485. doi: 10.4236/ce.2021.123033

Asadzadeh, H. (2018). Anticipating university students' academic performance based on their cognitive styles and academic procrastination. J. Edu. Strat. Med. Sci. 11, 10-39.

Baguri, E. M., Roslan, S., and Ahmad, N. (2020). Time perspectives as predictors of academic procrastinations. Inter.J. Acad. Res. Bus. Soc. Sci. 10, 351-366. doi: 10.6007/IJARBSS/v10-i16/8317

Balkis, M., and Duru, E. (2017). Gender differences in the relationship between academic procrastination, satisfaction with academic life and academic performance. Electron. J. Res. Educ. Psychol. 15, 105-125. doi: 10.14204/ ejrep. 41.16042

Bashir, L., and Gupta, S. (2019). A deeper look into the relationship between academic procrastination and academic performance among university students. Res. Guru 12, 531-540.

Baumeister, R. F., and Heatherton, T. F. (1996). Self-regulation failure: An overview. Psychol. Inq. 7, 1-15. doi: 10.1207/s15327965pli0701_1

Baumeister, R. F., Vohs, K. D., and Tice, D. M. (2007). The strength model of self-control. Curr. Dir. Psychol. Sci. 16, 351-355. doi: 10.1111/j.1467-8721.2007.00534.x

Beck, B. L., Koons, S. R., and Milgrim, D. L. (2000). Correlates and consequences of behavioral procrastination: The effects of academic procrastination, selfconsciousness, self-esteem and self-handicapping. J. Soc. Behav. Pers. 15:3

Bernardo, A., Esteban, M., Cervero, A., Cerezo, R., and Herrero, F. J. (2019). The influence of self-regulation behaviors on university students' intentions of persistence. Front. Psychol. 10:2284. doi: 10.3389/fpsyg.2019.02284

Biwer, F., Wiradhany, W., Oude Egbrink, M., Hospers, H., Wasenitz, S., Jansen, W., et al. (2021). Changes and adaptations: how university students self-regulate their online learning During the COVID-19 pandemic. Front. Psychol. 12:642593. doi: $10.3389 /$ fpsyg.2021.642593

Blunt, A., and Pychyl, T. A. (1998). Volitional action and inaction in the lives of undergraduate students: state orientation, procrastination and proneness to boredom. Personal. Individ. Differ. 24, 837-846. doi: 10.1016/S0191-8869(98)00018-X

Blunt, A. K., and Pychyl, T. A. (2000). Task aversiveness and procrastination: a multi-dimensional approach to task aversiveness across stages of personal projects. Personal. Individ. Differ. 28, 153-167. doi: 10.1016/S0191-8869(99)00091-4

Broadbent, J. (2017). Comparing online and blended learner's self-regulated learning strategies and academic performance. Internet High. Educ. 33, 24-32. doi: 10.1016/j.iheduc.2017.01.004

Broadbent, J., and Fuller-Tyszkiewicz, M. (2018). Profiles in self-regulated learning and their correlates for online and blended learning students. Educ. Technol. Res. Dev. 66, 1453-1455. doi: 10.1007/s11423-018-9595-9

Bui, N. H. (2007). Effect of evaluation threat on procrastination behavior. J. Soc. Psychol. 147, 197-209. doi: 10.3200/SOCP.147.3.197-209

Caprara, G. V., Barbaranelli, C., De Carlo, N. A., and Robusto, E. (eds.). (2006). Multidimensional Personality Profile. Milano: Franco Angeli.

Colthorpe, K., Ogiji, J., Ainscough, L., Zimbardi, K., and Anderson, S. (2017). Effect of metacognitive prompts on undergraduate pharmacy students' selfregulated learning behavior. Am. J. Pharm. Educ. 83:6646. doi: 10.5688/ajpe6646

Crego, A., Carrillo-Diaz, M., Armfield, J. M., and Romero, M. (2016). Stress and academic performance in dental students: The role of coping strategies and examination-related self-efficacy. J. Dent. Educ. 80, 165-172. doi: 10.1002/j. 0022-0337.2016.80.2.tb06072.x related to the accuracy or integrity of any part of it are appropriately investigated and resolved. All authors read and approved the final manuscript.

Daulay, A. A., Daharnis, D., and Afdal, A. (2018). "The role of counselor in developing Student's assertive behavior," in Education, Social Sciences and Technology Application in Digital Era. eds. I. Ifdil and Z. Ardi (Padang, Indonesia: Fakultas Ilmu Pendidikan UNP), 201-206.

Day, V., Mensink, D., and O'Sullivan, M. (2014). Patterns of academic procrastination. J. College Read. Learn. 30, 120-134. doi: $10.1080 / 10790195.2000 .10850090$

de la Fuente, J., Paoloni, P., Kauffman, D., Yilmaz Soylu, M., Sander, P., and Zapata, L. (2020). Big five, self-regulation, and coping strategies as predictors of achievement emotions in undergraduate students. Int. J. Environ. Res. Public Health 17:3602. doi: 10.3390/ijerph17103602

de la Fuente, J., Zapata, L., Martínez-Vicente, J. M., Sander, P., and Cardelle-Elawar, M. (2015). The role of personal self-regulation and regulatory teaching to predict motivational-affective variables, achievement, and satisfaction: a structural model. Front. Psychol. 6:399. doi: 10.3389/ fpsyg.2015.00399

de la Fuente-Arias, J. (2017). Theory of self- vs. externally-regulated learning TM: fundamentals, evidence, and applicability. Front. Psychol. 8:1675. doi: 10.3389/fpsyg.2017.01675

de Palo, V., Monacis, L., Miceli, S., Sinatra, M., and Di Nuovo, S. (2017). Decisional procrastination in academic settings: The role of metacognitions and learning strategies. Front. Psychol. 8:973. doi: 10.3389/fpsyg.2017. 00973

Delaval, M., Michinov, N., Le Bohec, O., and Le Hénaff, B. (2017). How can students' academic performance in statistics be improved? Testing the influence of social and temporal-self comparison feedback in a web-based training environment. Interact. Learn. Environ. 25, 35-47. doi: $10.1080 / 10494820.2015 .1090456$

Diotaiuti, P., Valente, G., and Mancone, S. (2021b). Development and preliminary Italian validation of the emergency response and psychological adjustment scale. Front. Psychol. 12:687514. doi: 10.3389/fpsyg.2021.687514

Diotaiuti, P., Valente, G., and Mancone, S. (2021c). Validation study of the Italian version of temporal focus scale: psychometric properties and convergent validity. BMC Psychol 9:19. doi: 10.1186/s40359-020-00510-5

Diotaiuti, P., Valente, G., Mancone, S., Falese, L., Bellizzi, F., Anastasi, D., et al. (2021a). Perception of risk, self-efficacy and social trust during the diffusion of Covid-19 in Italy. Int. J. Environ. Res. Public Health 18:3427. doi: 10.3390/ ijerph 18073427

Diotaiuti, P., Valente, G., Mancone, S., and Grambone, A. (2020). Psychometric properties and a preliminary validation study of the Italian brief version of the communication styles inventory (CSI-B/I). Front. Psychol. 11:1421. doi: 10.3389 /fpsyg.2020.01421

Dresel, M., Schmitz, B., Schober, B., Spiel, C., Ziegler, A., Engelschalk, T., et al. (2015). Competencies for successful self-regulated learning in higher education: structural model and indications drawn from expert interviews. Stud. High. Educ. 40, 454-470. doi: 10.1080/03075079.2015.1004236

Duckworth, A. L., Taxer, J., Eskreis-Winkler, L., Galla, B. M., and Gross, J. J. (2019). Self-control and academic achievement. Annu. Rev. Psychol. 70, 373-399. doi: 10.1146/annurev-psych-010418-103230

Eckert, M., Ebert, D. D., Lehr, D., Sieland, B., and Berking, M. (2016). Overcome procrastination: enhancing emotion regulation skills reduce procrastination. Learn. Individ. Differ. 52, 10-18. doi: 10.1016/j.lindif.2016.10.001

Effert, B. R., and Ferrari, J. R. (1989). Decisional procrastination: examining personality correlates. J. Soc. Behav. Pers. 4, 151-156.

Ferrari, J. R. (1991). Self-handicapping by procrastinators: protecting self-esteem, social-esteem, or both? J. Res. Pers. 25, 245-261. doi: 10.1016/0092-6566(91)90018-L

Ferrari, J. R. (2001). Procrastination as self-regulation failure of performance: effects of cognitive load, self-awareness, and time limits on 'working best under pressure. Eur. J. Personal. 15, 391-406. doi: 10.1002/per.413

Ferrari, J. R., O'Callaghan, J., and Newbegin, I. (2005). Prevalence of procrastination in the United States, United Kingdom, and Australia: arousal and avoidance delays among adults. N. Am. J. Psychol. 7. 
Ferrari, J. R., and Tice, D. M. (2000). Procrastination as a self-handicap for men and women: a task-avoidance strategy in a laboratory setting. J. Res. Pers. 34, 73-83. doi: 10.1006/jrpe.1999.2261

Frazier, P., Gabriel, A., Merians, A., and Lust, K. (2018). Understanding stress as an impediment to academic performance. J. Am. Coll. Heal. 67, 1-9. doi: 10.1080/07448481.2018.1499649

Garzón-Umerenkova, A., de la Fuente, J., Amate, J., Paoloni, P. V., Fadda, S., and Pérez, J. F. (2018). A linear empirical model of self-regulation on flourishing, health, procrastination, and achievement, Among university students. Front. Psychol. 9:536. doi: 10.3389/fpsyg.2018.00536

Garzón-Umerenkova, A., Gil-Flores, J., and Fuente, J. (2020). Demographic, academic and personal traits associated with three types of procrastination in university students. Bordón 72, 59-65.

Ghosh, R., and Roy, S. (2017). Relating multidimensional perfectionism and academic procrastination among Indian university students. Is there any gender divide? Gender Manag. 32, 518-534. doi: 10.1108/gm-01-2017-0011

Goroshit, M. (2018). Academic procrastination and academic performance: An initial basis for intervention. J. Prev. Interv. Community 46, 131-142. doi: 10.1080/10852352.2016.1198157

Goubet, K. E., and Chrysikou, E. G. (2019). Emotion regulation flexibility: gender differences in context sensitivity and repertoire. Front. Psychol. 10:935. doi: $10.3389 /$ fpsyg.2019.00935

Grunschel, C., Schwinger, M., Steinmayr, R., and Fries, S. (2016). Effects of using motivational regulation strategies on students' academic procrastination, academic performance, and well-being. Learn. Individ. Differ. 49, 162-170. doi: 10.1016/j.lindif.2016.06.008

Gustavson, D. E., and Miyake, A. (2017). Academic procrastination and goal accomplishment: A combined experimental and individual differences investigation. Learn. Individ. Differ. 54, 160-172. doi: 10.1016/j.lindif.2017.01.010

Harrington, N. (2005). It's too difficult! Frustration intolerance beliefs and procrastination. Personal. Individ. Differ. 39, 873-883. doi: 10.1016/j. paid.2004.12.018

Hayes, A. F. (2017). Introduction to mediation, moderation, and conditional process analysis: A regression-based approach. United States, NY: Guilford publications.

He, S., and Zhang, Z. (2019). The Relationship between Junior Students' Selfregulation of Time Management and Academic Performance: the Mediating Effect of Independent Learning. Proceedings of the 2nd International Seminar on Education Research and Social Science (ISERSS 2019).

Hen, M., and Goroshit, M. (2014). Academic procrastination, emotional intelligence, academic self-efficacy, and GPA: A comparison between students with and without learning disabilities. J. Learn. Disabil. 47, 116-124. doi: 10.1177/0022219412439325

Howell, A. J., and Watson, D. C. (2007). Procrastination: associations with achievement goal orientation and learning strategies. Personal. Individ. Differ. 43, 167-178. doi: 10.1016/j.paid.2006.11.017

Jalagat, R. (2017). Assessing the relationship of time management and academic performance of the business students in Al-Zahra College for women. Eur. Bus. Manag. 3, 1-8.

Kim, K. R., and Seo, E. H. (2015). The relationship between procrastination and academic performance: A meta-analysis. Personal. Individ. Differ. 82, 26-33. doi: 10.1016/j.paid.2015.02.038

Klassen, R. M., Ang, R. P., Chong, W. H., Krawchuk, L. L., Huan, V. S., Wong, I. Y., et al. (2009). A cross-cultural study of adolescent procrastination. J. Res. Adolesc. 19, 799-811. doi: 10.1111/j.1532-7795.2009.00620.x

Klassen, R. M., Krawchuk, L. L., and Rajani, S. (2008). Academic procrastination of undergraduates: Low self-efficacy to self-regulate predicts higher levels of procrastination. Contemp. Educ. Psychol. 33, 915-931. doi: 10.1016/j. cedpsych.2007.07.001

Kyung, R. K., and Eun, H. S. (2015). The relationship Between procrastination and academic performance: A meta-analysis. Personal. Individ. Differ. 82, 26-33.

Lasane, T. P., and Jones, J. M. (2000). When socially induced temporal myopia interferes with academic goal-setting. J. Soc. Behav. Pers. 15, 75-86.

Levasseur, L., Shipp, A., Fried, Y., Rousseau, D., and Zimbardo, P. (2020). New perspectives on time perspective and temporal focus. J. Organ. Behav. 41, 235-243. doi: 10.1002/job.2435

Limone, P., Sinatra, M., Ceglie, F., and Monacis, L. (2020). Examining procrastination among university students through the lens of the selfregulated learning model. Behav. Sci. 10:184. doi: 10.3390/bs10120184
Maddineshat, M., Yousefzadeh, M. R., and Hashemi, M. (2019). Evaluating the academic advisors' communication skills according to the students living in dormitory. J. Educ. Health Promot. 8:62. doi: 10.4103/jehp.jehp_ 315_18

Madhan, B., Kumar, C. S., Naik, E. S., Panda, S., Gayathri, H., and Barik, A. K. (2012). Trait procrastination among dental students in India and its influence on academic performance. J. Dent. Educ. 76, 1393-1398. doi: 10.1002/j.0022-0337.2012.76.10.tb05397.x

Mandap, C. M. (2016). Examining the differences in procrastination tendencies among university students. Int. J. Educ. Res. 4, 431-436.

Mariani, M. G., and Ferrari, J. R. (2012). Adult inventory of procrastination scale (AIP): A comparison of models with an Italian sample. Testing, Psycho. Method. Appl. Psychol. 19, 3-14.

Maxwell, S. E., and Cole, D. A. (2011). Bias in cross-sectional analyses of longitudinal mediation: partial and complete mediation Under an autoregressive model, multivariate. Behav. Res. Ther. 46, 816-841. doi: $10.1080 / 00273171.2011 .606716$

McCown, W., and Johnson, J. (1989). Procrastination, a principal components analysis. Personal. Individ. Differ. 10, 197-202. doi: 10.1016/0191-8869(89)90204-3

Medrano, L. A., Flores, E., Moretti, L. S., and Pereno, G. L. (2016). Effects of induction of positive and negative emotional states on academic self-efficacy beliefs in college students. Psicol. Educ. 22, 135-141. doi: 10.1016/j. pse.2015.03.003

Meyer, C. L. (2000). Academic procrastination and self-handicapping: Gender differences in response to noncontingent feedback. J. Soc. Behav. Pers. 15:87.

Michałowski, J. M., Koziejowski, W., Drozdziel, D., and Harciarek, M. (2017). Error processing deficits in academic procrastinators anticipating monetary punishment in a go/no-go study. Personal. Individ. Differ. 117, 198-204. doi: $10.1016 /$ j.paid.2017.06.010

Mohammadi Bytamar, J., Saed, O., and Khakpoor, S. (2020). Emotion regulation difficulties and academic procrastination. Front. Psychol. 11:524588. doi: 10.3389/fpsyg.2020.524588

Mohammadi Bytamar, J., Zenoozian, S., Dadashi, M., Saed, O., Hemmat, A., and Mohammadi, G. (2018). Prevalence of academic procrastination and its association with metacognitive beliefs in Zanjan university of medical sciences. Iran. J. Med. Educ. Dev. 10, 84-97.

Morales-Rodríguez, F., and Pérez-Mármol, J. (2019). The role of anxiety, coping strategies, and emotional intelligence on general perceived self-efficacy in university students. Front. Psychol. 10:1689. doi: 10.3389/fpsyg.2019.01689

Morgan, M. (1985). Self monitoring of attained subgoals in private study. J. Educ. Psychol. 77, 623-630. doi: 10.1037/0022-0663.77.6.623

Newman, B. N., Strickler, J. G., O’Brien, C., Lui, T. G., and Lynch, M. (2019). Deconstructing perfectionism in college students: patterns of behavior, emotion, and cognition. Personal. Individ. Differ. 145, 106-111. doi: 10.1016/j. paid.2019.03.030

Nordby, K., Løkken, R. A., and Pfuhl, G. (2019). Playing a video game is more than mere procrastination. BMC Psychol. 7:33. doi: 10.1186/ s40359-019-0309-9

Onwuegbuzie, A. J. (2004). Academic procrastination and statistics anxiety. Assess. Eval. High. Educ. 29, 3-19. doi: 10.1080/0260293042000160384

Özer, B., Demir, A., and Ferrari, J. (2009). Exploring academic procrastination Among Turkish students: Possible gender differences in prevalence and reasons. J. Soc. Psychol. 149, 241-257. doi: 10.3200/SOCP.149.2.241-257

Patrzek, J., Grunschel, C., and Fries, S. (2012). Academic procrastination: the perspective of university counsellors. Int. J. Adv. Couns. 34, 185-201. doi: 10.1007/s10447-012-9150-Z

Pelikan, E. R., Lüftenegger, M., Holzer, J., Korlat, S., Spiel, C., Schober, B., et al. (2021). Learning during COVID-19: the role of self-regulated learning, motivation, and procrastination for perceived competence. Z Erziehungswiss 24, 393-418. doi: 10.1007/s11618-021-01002-x

Petruccelli, F., Diotaiuti, P., Verrastro, V., Petruccelli, I., Carenti, M. L. De Berardis, D., et al. (2014). Obsessive-compulsive aspects and pathological gambling in an Italian sample. Biomed. Res. Int. 2014:167438. doi: $10.1155 / 2014 / 167438$

Pychyl, T. A., and Flett, G. L. (2012). Procrastination and self-regulatory failure: An introduction to the special issue. J. Ration. Emot. Cogn. Behav. Ther. 30, 203-212. doi: 10.1007/s10942-012-0149-5 
Pychyl, T. A., and Sirois, F. M. (eds). (2016). Procrastination, Emotion Regulation, and Well-Being. PROCRASTINATION, Health, and Well-Being, (New York, NY: Elsevier), 163-188.

Rabin, L. A., Fogel, J., and Nutter-Upham, K. E. (2010). Academic procrastination in college students: The role of self-reported executive function. J. Clin. Exp. Neuropsychol. 33, 344-357. doi: 10.1080/13803395.2010.518597

Rakes, G. C., and Dunn, K. E. (2010). The impact of online graduate students' motivation and self-regulation on academic procrastination. J. Inter. Learn. 9, 78-94.

Rasheed, R. A., Kamsin, A., Abdullah, N. A., Kakudi, H. A., Ali, A. S., Musa, A. S., et al. (2020). Self-regulated learning in flipped classrooms: A systematic literature review. Inter. J. Inform. Educ. Technol. 10, 848-853. doi: $10.18178 /$ ijiet.2020.10.11.1469

Rothblum, E. D., Solomon, L. J., and Murakami, J. (1986). Affective, cognitive, and behavioral differences between high and low procrastinators. J. Couns. Psychol. 33:387. doi: 10.1037/0022-0167.33.4.387

Rustemeyer, R., and Rausch, A. (2007). Academic procrastination: coherence of expectancy-value variables. Psychol. Erzieh. Unterr. 54, 47-58.

Saklofske, D. H., Austin, E. J., Mastoras, S. M., Beaton, L., and Osborne, S. E. (2012). Relationships of personality, affect, emotional intelligence and coping with student stress and academic success: different patterns of association for stress and success. Learn. Individ. Differ. 22, 251-257. doi: 10.1016/j. lindif.2011.02.010

Sánchez-Álvarez, N., Berrios Martos, M. P., and Extremera, N. (2020). A metaanalysis of the relationship Between emotional intelligence and academic performance in secondary education: A multi-stream comparison. Front. Psychol. 11:1517. doi: 10.3389/fpsyg.2020.01517

Schouwenburg, H. C. (1992). Procrastinators and fear of failure: an exploration of reasons for procrastination. Eur. J. Personal. 6, 225-236. doi: 10.1002/ per. 2410060305

Sharaf, N., Obeidat, A., Jadd, G., Al-tannir, M., Aly, M., and Alkattan, K. (2016). Academic performance and time Management of Medical Students in Saudi Arabia. Inter. J. e-Healthcare Inform. Systems 3, 90-93. doi: 10.20533/ ijehis.2046.3332.2016.0013

Shi, M., Zhai, X., Li, S., Shi, Y., and Fan, X. (2021). The relationship between physical activity, Mobile phone addiction, and irrational procrastination in Chinese college students. Int. J. Environ. Res. Public Health 18:5325. doi: 10.3390/ijerph 18105325

Sirois, F., and Pychyl, T. (2013). Procrastination and the priority of short-term mood regulation: consequences for future self. Soc. Personal. Psychol. Compass 7, 115-127. doi: $10.1111 / \mathrm{spc} 3.12011$

Solomon, L. J., and Rothblum, E. D. (1984). Academic procrastination: frequency and cognitive-behavioral correlates. J. Couns. Psychol. 31:503. doi: 10.1037/0022-0167.31.4.503

Steel, P. (2007a). The nature of procrastination: A meta-analytic and theoretical review of quintessential self-regulatory failure. Psychol. Bull. 133, 65-94. doi: 10.1037/0033-2909.133.1.65

Steel, P. (2007b). Procrastination and performance. Pers. Individ. Differ. 30, 54-63.

Steel, P., and Ferrari, J. (2013). Sex, education and procrastination: An epidemiological study of procrastinators' characteristics from a global sample. Eur. J. Personal. 27, 51-58. doi: 10.1002/per.1851

Stewart, M., Stott, T., and Nuttall, A. M. (2016). Study goals and procrastination tendencies at different stages of the undergraduate degree. Stud. High. Educ. 41, 2028-2043. doi: 10.1080/03075079.2015.1005590

Stöber, J., and Joormann, J. (2001). Worry, procrastination, and perfectionism: differentiating amount of worry, pathological worry, anxiety, and depression. Cogn. Ther. Res. 25, 49-60. doi: 10.1023/A:1026474715384
Svartdal, F., Dahl, T. I., Gamst-Klaussen, T., Koppenborg, M., and Klingsieck, K. B. (2020). How study environments Foster academic procrastination: overview and recommendations. Front. Psychol. 11:540910. doi: 10.3389/ fpsyg. 2020.540910

Tezer, M. (2020). Academic procrastination behaviours and problematic internet usage of high school students during the COVID-19 pandemic period. Inter. J. Special Educ. Inform. Technol. 6, 1-17. doi: 10.18844/jeset.v6i1. 5490

Tice, D. M., and Bratslavsky, E. (2000). Giving in to feel good: The place of emotion regulation in the context of general self-control. Psychol. Inq. 11, 149-159. doi: 10.1207/S15327965PLI1103_03

Tice, D. M., Bratslavsky, E., and Baumeister, R. F. (2001). Emotional distress regulation takes precedence over impulse control: If you feel bad, do it! J. Pers. Soc. Psychol. 80, 53-67. doi: 10.1037/0022-3514.80.1.53

Van Eerde, W., and Klingsieck, K. (2018). Overcoming procrastination? A metaanalysis of intervention studies. Edu. Res. Rev. 25, 73-85.

Visser, L., Korthagen, F. A. J., and Schoonenboom, J. (2018). Differences in learning characteristics between students with high, average, and low levels of academic procrastination: students' views on factors influencing their learning. Front. Psychol. 9:808. doi: 10.3389/fpsyg.2018.00808

Vizoso Gómez, C., Rodríguez, C., and Arias-Gundín, O. (2018). Coping, academic engagement and performance in university students. High. Educ. Res. Dev. 37, 1515-1529. doi: 10.1080/07294360.2018.1504006

Wypych, M., Matuszewski, J., and Dragan, W. (2018). Roles of impulsivity, motivation, and emotion regulation in procrastination - path analysis and comparison Between students and non-students. Front. Psychol. 9:891. doi: 10.3389/fpsyg.2018.00891

Yilmaz, M. (2017). The relation between academic procrastination of university students and their assignment and exam performances: The situation in distance and face-to-face learning environments. J. Educ. Train. Stud. 5, 146-157. doi: 10.11114/jets.v5i9.2545

Zhong, J. (2013). Preliminary study on the relationship between procrastination and physical activity of college students. J. Beijing Sport Univ. 20, $21-22$.

Zhou, M. (2020). Gender differences in procrastination: The role of personality traits. Curr. Psychol. 39, 1445-1453. doi: 10.1007/s12144-018-9851-5

Ziegler, N., and Opdenakker, M. C. (2018). The development of academic procrastination in first-year secondary education students: The link with metacognitive self-regulation, self-efficacy, and effort regulation. Learn. Individ. Differ. 64, 71-82. doi: 10.1016/j.lindif.2018.04.009

Conflict of Interest: The authors declare that the research was conducted in the absence of any commercial or financial relationships that could be construed as a potential conflict of interest.

Publisher's Note: All claims expressed in this article are solely those of the authors and do not necessarily represent those of their affiliated organizations, or those of the publisher, the editors and the reviewers. Any product that may be evaluated in this article, or claim that may be made by its manufacturer, is not guaranteed or endorsed by the publisher.

Copyright (๑) 2021 Diotaiuti, Valente, Mancone and Bellizzi. This is an open-access article distributed under the terms of the Creative Commons Attribution License (CC BY). The use, distribution or reproduction in other forums is permitted, provided the original author(s) and the copyright owner(s) are credited and that the original publication in this journal is cited, in accordance with accepted academic practice. No use, distribution or reproduction is permitted which does not comply with these terms. 